\title{
The Analytic Study on the Heavy Steel Plate Snake Rolling with the Same Roll Diameters
}

\author{
Lian-yun Jiang $\mathbb{D}^{1,2}$ Qing-cheng Meng, ${ }^{1,2}$ Chun-jiang Zhao $\mathbb{i D}^{1,2}$ \\ Shou-xin Wang, ${ }^{1}$ and Yan-wei Liu ${ }^{1}$ \\ ${ }^{1}$ School of Mechanical Engineering, Taiyuan University of Science and Technology, Taiyuan 030024, China \\ ${ }^{2}$ Coordinative Innovation Center of Taiyuan Heavy Machinery Equipment, Taiyuan University of Science and Technology, \\ Taiyuan 030024, China
}

Correspondence should be addressed to Lian-yun Jiang; jiangly2015@126.com

Received 21 June 2018; Accepted 22 October 2018; Published 7 November 2018

Academic Editor: Surajit Kumar Paul

Copyright (C) 2018 Lian-yun Jiang et al. This is an open access article distributed under the Creative Commons Attribution License, which permits unrestricted use, distribution, and reproduction in any medium, provided the original work is properly cited.

\begin{abstract}
The deformation in the inner region along the thickness of the heavy steel plate can be improved by snake rolling method. Then the microstructure and property will be refined and the crack in the inner region may be avoided. Therefore, the in-depth research on snake rolling method mechanics parameter modeling should be conducted to guide production. A snake rolling process with the same roll diameters and different angular velocity was conducted in this paper. The rolling deformation zone will be divided into back slip zone, front slip zone, cross shear zone, and reverse deflection zone according to the direction of the friction during the snake rolling process. The four zones may not exist at the same time. The boundary conditions of existence of the back slip zone, front slip zone, and cross shear zone were established according to the relationship between threading angle and neutral angle. The calculating models which were used to calculate the snake rolling mechanical parameters including the rolling force and rolling torque were set up. The calculated models of unit compressive pressure in the four zones were set up by the slab method, and on this basis the accurate calculating models of the rolling force and rolling torque were set up according to the composition of the rolling deformation zone and the boundary condition. The mechanical parameters were calculated by the analytical method and the numerical method, and the relative deviation is less than $6 \%$ which can satisfy the industrial requirement. The present analytical model can predict the characteristics during snake rolling easily and quickly and it is also suitable for online control applications.
\end{abstract}

\section{Introduction}

The heavy steel plate with fine performance has been widely used in military equipment, warship, nuclear power, offshore platform, pressure vessel, heavy machinery, and so on. The production capacity of the cast ingot and the opening degree of the mill make it difficult to satisfy the required rolling reduction ratio [1]. Then the heavy steel plate with fine performance in the inner region cannot be easily obtained. Thus, one of the core problems that constrain the heavy steel plate rolling production process is the lack of sufficient deformation produced in the inner region, and then the problem of microstructure and properties or the crack will appear in the inner region.

Asymmetrical rolling has been used in cold strip rolling production, and the application results show that the inner grains have been refined compared to the symmetrical rolling. Therefore, the inner region deformation can be improved by the asymmetrical rolling [2-4]. The heavy steel plate curvature problem will appear after asymmetrical rolling and the plate threading in the next pass, or the plate rotation will be difficult to achieve. The plate curvature problem that was produced during asymmetrical rolling for thin strip steel can be solved by the tension between the two stands, but it is not feasible to solve the plate curvature problem that is produced in the heavy steel plate asymmetrical rolling process by this method. The deformation in the inner region can also be improved by the snake rolling process, and the plate curvature after rolling can also be kept well $[5,6]$, so this problem can be solved by the snake rolling method which is a kind of asymmetrical rolling. The plate curvature and the strain along the thickness calculation or prediction 
must be conducted on the basis of the mechanical parameters modeling. Therefore, the in-depth research on snake rolling mechanical parameters modeling will be of vital importance for snake rolling industrial application.

Currently, some scholars used the slab method, stream function method, and finite element method to study the rolling force and rolling torque modeling during asymmetrical rolling. Hwang Y. M. set up the mechanical parameters calculating models of asymmetrical hot-sheet rolling and asymmetrical clad sheet rolling, and the models assume that the normal stress was well distributed and the shear stress in the cross section was neglected $[7,8]$. G.Y. Tzou and X. Liu constructed a model used to calculate the minimum thickness for asymmetrical hot and cold PV rolling which considered the effect of friction factor $[9,10]$. H. Gao studied the influence of friction coefficient ratio on the cross shear deformation and rolling pressure and torque during asymmetrical rolling process by the slab method [4]. Tian Y. analyzed the asymmetrical rolling by slab method, and the deformation zone was divided into three zones according to the direction of the friction [11]. The contact arc was replaced by parabola, and the constant surface friction status was adopted during the analysis. M. Salimi provided an analytical model to calculate the strip curvature based on the slab method and modified slab method $[12,13]$. F. Afrouz provided an analytical model of asymmetric rolling of unbounded clad sheets which considered the influence of the shear effects [14]. M. Kadkhodaei and S.H. Zhang set up the calculating models of mechanical parameters by the genetic algorithm and slab method $[15,16]$. Su-wen Chen and A. Parvizi constructed the mechanical parameters calculating models by the slab method during large cylindrical shell rolling $[17,18]$.

The mechanical parameters calculation models established by the above scholars are all based on the consideration of the deformation zone composed of back slip zone, cross shear zone, and front slip zone. The deformation zone of asymmetrical rolling has a variety of composition forms. The composition form of the deformation zone is different, and the boundary conditions corresponding to it are different. At present, no mechanical parameters calculation model considering the composition form of the deformation zone has been found. Therefore, it is necessary to establish a mechanical parameters calculation model that takes into account the composition form of the deformation zone.

The snake rolling process has been used in the thick aluminum plate rolling process and achieved certain progress. S.Y. Li and G.F. Xu studied the microstructure and texture of aluminum alloy plate snake rolling and confirmed that snake rolling can refine the inner region grain of aluminum alloy plate and improve the mechanical properties of the inner region $[19,20]$. T. Zhang and J.X. Yang used the numerical method and experimental method to study the bending behavior and strain heterogeneity distribution of thick aluminum alloy plate snake rolling $[21,22]$. T. Zhang employed the numerical method and the experimental method to study the strain distribution and temperature distribution of thick aluminum alloy plate snake rolling [23-25].

Three zones (back slip zone, front slip zone, and cross shear zone) will be divided in the asymmetrical rolling deformation zone. The distribution of the rolling deformation zone during snake rolling is different from asymmetrical rolling because of the offset distance of work rolls. Consequently, the calculating models that were used to calculate asymmetrical rolling mechanical parameters cannot be used to calculate snake rolling mechanical parameters. And the calculating models that were used to calculate snake rolling mechanical parameters taking into account the composition forms of the deformation zone should be set up in this paper.

\section{Snake Rolling Basic Parameters Modeling}

The necessary assumptions that need to be made in the process of establishing a mathematical model of snake rolling are as follows:

(1) The width-to-thickness ratio of steel plate is very large for the snake rolling process. The width spread of the heavy steel plate is relatively small which can be neglected. Hence the heavy steel plate snake rolling model can be simplified as plane strain problem.

(2) The deformation of the heavy steel plate is very large compared to the deformation of the work rolls, and the deformation of the work rolls can be neglected. As a result, the work rolls were assumed as a rigid body.

(3) The diameter of the top and bottom work rolls are the same, and the angular velocity of the bottom work roll is larger than the angular velocity of the top work roll, which is $R_{1}=R_{2}=R ; n_{2}>n_{1}$.

2.1. The Threading Angle Calculation. There is a roll offset between the top and bottom work rolls during snake rolling, and reductions of the top and bottom work rolls are different. Figure 1 shows the geometric relationship of the snake rolling. $A$ and $B$ are threading points, which are, respectively, regarded as $A C$ and $B D$ parallel to the rolling direction, and the bottom work roll center which is in the vertical direction intersects at $C$ and $D$ points. From the geometric relationship in Figure 1, it can be obtained as follows:

for the top work roll:

$$
l^{\prime}=\sqrt{R_{1}^{2}-\left(R_{1}-\Delta h_{1}\right)^{2}}-d
$$

for the bottom work roll:

$$
l^{\prime}=\sqrt{R_{2}^{2}-\left(R_{2}-\Delta h_{2}\right)^{2}}
$$

along the vertical direction:

$$
\Delta h_{1}+\Delta h_{2}=H-h_{0}
$$

combining (1) (3):

$$
\begin{aligned}
\Delta h_{1} & =\frac{a b+R+\sqrt{2 a b R+R^{2}-a^{2}}}{b^{2}+1} \\
\Delta h_{2} & =H-h_{0}-\Delta h_{1} \\
& =H-h_{0}-\frac{a b+R+\sqrt{2 a b R+R^{2}-a^{2}}}{b^{2}+1}
\end{aligned}
$$


where $a=\left(2 R\left(H-h_{0}\right)-\left(H-h_{0}\right)^{2}-d^{2}\right) / 2 d, b=(2 R-$ $\left.H+h_{0}\right) / d$.

Total reduction:

$$
\Delta h=\Delta h_{1}+\Delta h_{2}=H-h_{0}
$$

and, as shown in Figure $1, \Delta h_{1}=R_{1}-R_{1} \cdot \cos \alpha_{1}$. Hence it is concluded that

$$
\cos \alpha_{1}=1-\frac{\Delta h_{1}}{R}
$$

In the same way:

$$
\cos \alpha_{2}=1-\frac{\Delta h_{2}}{R}
$$

Because the threading angle $\alpha_{1}$ and $\alpha_{2}$ are very small, $\alpha=$ $\max \left(\alpha_{1}, \alpha_{2}\right), \alpha<10^{\circ} \sim 15^{\circ}$, taking $\sin (\alpha / 2) \approx \alpha / 2$ and then

$$
\begin{aligned}
& \alpha_{1} \approx \sqrt{\frac{2 \Delta h_{1}}{R}} \\
& \alpha_{2} \approx \sqrt{\frac{2 \Delta h_{2}}{R}} .
\end{aligned}
$$

Length of the deformation zone is as follows.

$$
l=\sqrt{R_{1}^{2}-\left(R_{1}-\Delta h_{1}\right)^{2}}=\sqrt{2 R \cdot \Delta h_{1}-\Delta h_{1}^{2}}
$$

2.2. The Neutral Angle Calculation. The neutral angles of the top and bottom work rolls are also different because of the existence of the roll offset between the top and bottom work rolls and the difference of the angular velocity between the top and bottom work rolls.

The forward slips of the top and bottom work rolls are, respectively, as follows.

$$
\begin{aligned}
& S_{1}=\frac{v_{0}-v_{1}}{v_{1}} \\
& S_{2}=\frac{v_{0}-v_{2}}{v_{2}}
\end{aligned}
$$

According to the principle of metal equal flow during snake rolling,

$$
h_{\gamma_{1}} v_{\gamma_{1}}=h_{\gamma_{2}} v_{\gamma_{2}}=h_{0} v_{0}
$$

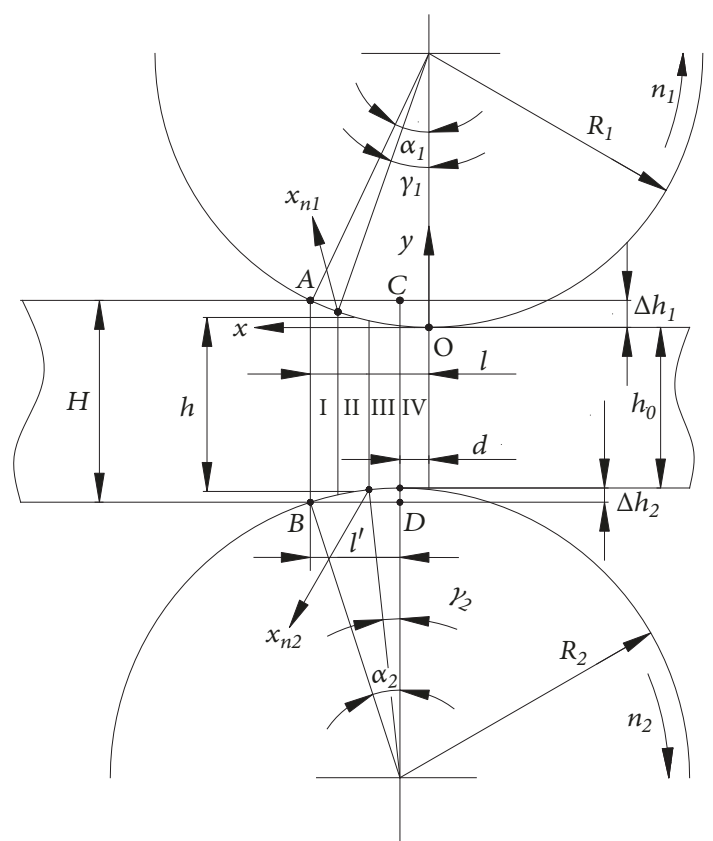

FIGURE 1: Schematic diagram of snake rolling plastic deformation.

Equations (14) and (15) will be obtained from Figure 1.

$$
\begin{aligned}
h_{\gamma_{1}}= & h_{0}+R-R \cos \gamma_{1}+R \\
& -\sqrt{R^{2}-R^{2} \sin ^{2} \gamma_{1}+2 R d \sin \gamma_{1}-d^{2}} \\
= & h_{0}+2 R-R \cos \gamma_{1} \\
& -\sqrt{R^{2} \cos ^{2} \gamma_{1}+2 R d \sin \gamma_{1}-d^{2}} \\
h_{\gamma_{2}=} & h_{0}+R-R \cos \gamma_{2}+R \\
& -\sqrt{R^{2}-R^{2} \sin ^{2} \gamma_{2}-2 R d \sin \gamma_{2}-d^{2}} \\
= & h_{0}+2 R-R \cos \gamma_{2} \\
& -\sqrt{R^{2} \cos ^{2} \gamma_{2}-2 R d \sin \gamma_{2}-d^{2}}
\end{aligned}
$$

Since $v_{\gamma_{1}}=v_{1} \cos \gamma_{1}, v_{\gamma_{2}}=v_{2} \cos \gamma_{2}$, substituting them into the (13) and (16), we obtain

$$
\begin{aligned}
& \frac{v_{0}}{v_{1}}=h_{\gamma_{1}} \frac{\cos \gamma_{1}}{h_{0}}, \\
& \frac{v_{0}}{v_{2}}=h_{\gamma_{2}} \frac{\cos \gamma_{2}}{h_{0}}
\end{aligned}
$$

so

$$
\begin{aligned}
S_{1} & =\frac{v_{0}}{v_{1}}-1=\left[h_{0}+2 R-R \cos \gamma_{1}\right. \\
& \left.-\sqrt{R^{2} \cos ^{2} \gamma_{1}+2 R d \cdot \sin \gamma_{1}-d^{2}}\right] \frac{\cos \gamma_{1}}{h_{0}}-1 .
\end{aligned}
$$


Since $2 R d \cdot \sin \gamma_{1}-d^{2}$ is much smaller than $R^{2} \cos ^{2} \gamma_{1}$, it can be ignored, so (17) can be simplified as follows.

$$
S_{1}=\left[h_{0}+2 R-2 R \cos \gamma_{1}\right] \frac{\cos \gamma_{1}}{h_{0}}-1
$$

As $\gamma_{1}$ is very small in general, so the equation can be further simplified as follows.

$$
S_{1}=\frac{2 R\left(1-\cos \gamma_{1}\right)}{h_{0}}
$$

Thus the neutral angle of the top work roll can be obtained as follows.

$$
\gamma_{1}=\arccos \left(1-\frac{S_{1} h_{0}}{2 R}\right)
$$

Similarly, the neutral angle of the bottom work roll can be obtained as follows.

$$
\gamma_{2}=\arccos \left(1-\frac{S_{2} h_{0}}{2 R}\right)
$$

\section{The Mechanical Parameters Modeling}

Figure 1 is a schematic diagram of the snake rolling plastic deformation, in which the origin of the coordinate system is located at the throwing point (point "O" in Figure 1) of the top work roll, and the $x$ axis direction is opposite to the rolling direction. The rolled pieces contact the bottom work roll firstly when the snake rolling process starts. Then the rolled pieces will be lifted, be moved forward, and contact with the top work roll with the action of the friction force of the bottom work roll. The rolled pieces can be threaded into the roll gap under the combined action of top and bottom work rolls. The positions of neutral points of the top and bottom work rolls are also different because of the existence of the roll offset between the top and bottom work rolls and the difference of the angular velocity between the top and bottom work rolls. Thus, the snake rolling plastic deformation zone can be divided into four different zones, as shown in Figure 1: I is back slip zone, II is cross shear zone, III is front slip zone, and IV is reverse deflection zone.

As shown in Figure 2, take out an element from the four different zones, respectively, in order to calculate the unit compressive pressure. The rolled pieces will contact the top and bottom work rolls at the same time in zone I and zone III. In zone I, as is shown in Figure 2(a), the directions of the friction stresses of rolled pieces top and bottom surfaces are the same with rolling direction, and rolled pieces can be threaded into the roll gap. The direction of friction stresses in zone III is opposite to zone I as is shown in Figure 2(c). In zone II, as is shown in Figure 2(b), the speed of rolled pieces is lower than the surface linear speed of the bottom work roll, but higher than the surface linear speed of the top work roll. Therefore, the direction of friction stress on the top contact surface of the rolled pieces is opposite to the rolling direction, but the direction of friction stress on the bottom contact surface of rolled pieces is the same as the rolling direction. The directions of friction stresses of the top and bottom contact surfaces are opposite in zone II, which makes the metal in the zone have a strong shearing effect and be favorable for the metal plastic deformation to be penetrated into the thickness center. The rolled pieces are affected only by the top work roll in zone IV, as is shown in Figure 2(d), and the speed of rolled pieces is higher than the surface linear speed of the top work roll, so the direction of the friction stress on the top contact surface of rolled pieces is opposite to the rolling direction.

The contact arc between the work rolls and rolled pieces was simplified as parabolic curve during the snake rolling process, so the rolling reduction of the top and bottom work rolls can be obtained at this basis: $\Delta h_{1}(x)=x^{2} /(2 R)$, $\Delta h_{2}(x)=(x-d)^{2} /(2 R)$. Hence the rolled pieces thickness in the $x$ cross section will be obtained: $h=h_{0}+\left[x^{2}+(x-\right.$ $\left.d)^{2}\right] /(2 R)$.

Equation (22) was obtained according to the equilibrium equation of the force along the horizontal direction for every element in the deformation:

$$
d\left(\sigma_{x} h\right)+\left(p_{1} \tan \theta_{1}+p_{2} \tan \theta_{2}-\tau_{e}\right) d x=0
$$

where $\tan \theta_{1} \approx x / R, \tan \theta_{2} \approx(x-d) / R$.

3.1. Yield Criterion. The Von-Mises yield criterion at any point is written as below.

$$
\begin{gathered}
\left(\sigma_{x}-\sigma_{y}\right)^{2}+\left(\sigma_{y}-\sigma_{z}\right)^{2}+\left(\sigma_{z}-\sigma_{x}\right)^{2} \\
+6\left(\tau_{x y}^{2}+\tau_{y z}^{2}+\tau_{z x}^{2}\right)=2 \sigma_{s}^{2}
\end{gathered}
$$

The $\tau_{y z}=\tau_{z x}=0$ for the plane strain condition, and $\sigma_{z}=$ $\left(\sigma_{x}+\sigma_{y}\right) / 2$ according to the flow rule. Substitute the two equations into (23), and (24) will be obtained.

$$
\frac{3}{2}\left(\sigma_{x}-\sigma_{y}\right)^{2}+6 \tau_{x y}^{2}=2 \sigma_{s}^{2}
$$

The shear stress $\tau_{x y}$ produced in the surface of the deformation zone will reach the maximum value $\tau_{s}=m k . m$ is friction factor; $k$ is mean yield shear stress and $k=\sigma_{s} / \sqrt{3}$. Thus the shear yield strength of the materials of rolled pieces can be obtained.

$$
\tau_{x y}=m k=\frac{m \sigma_{s}}{\sqrt{3}}
$$

Substituting (25) into (24), the yield criterion for rolled pieces materials can be obtained.

$$
\sigma_{x}-\sigma_{y}=\frac{2 \sigma_{s}}{\sqrt{3}} \sqrt{1-m^{2}}
$$

Considering $\sigma_{x}=q$ and $\sigma_{y}=-p$, the following relation was obtained.

$$
\sigma_{x}-\sigma_{y}=p+q=M=\frac{2 \sigma_{s}}{\sqrt{3}} \sqrt{1-m^{2}}
$$




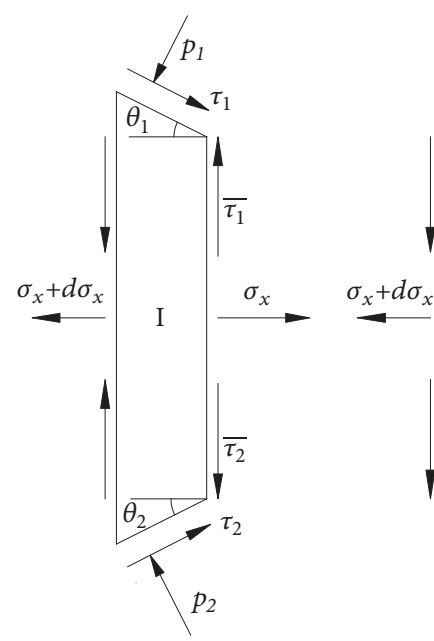

(a)

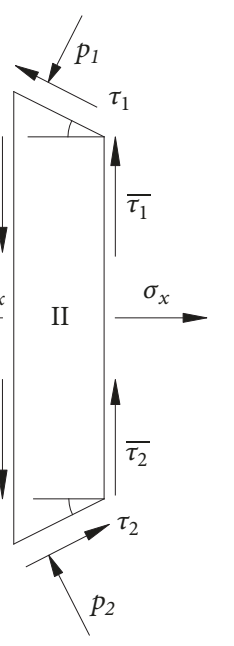

(b)

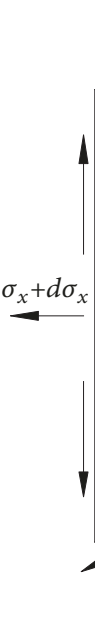

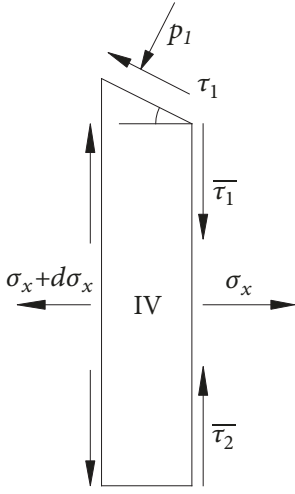

(d)

FIGURE 2: Stress states of a vertical element in four zones for $v_{2}>v_{1}$.

\subsection{Unit Compressive Pressure Modeling}

3.2.1. Zone $I\left(x_{n 1} \leq x \leq l\right)$. The forces in this zone have the following relationships:

$p_{1}=p-\tau_{1} \tan \theta_{1}, p_{2}=p-\tau_{2} \tan \theta_{2}, \tau_{e}=\tau_{1}+\tau_{2}$, and substituting them into (22), the following can be obtained.

$$
\begin{aligned}
& \left(h_{0}+\frac{x^{2}+(x-d)^{2}}{2 R}\right) \cdot \frac{d p}{d x} \\
& \quad=\frac{2 x-d}{R} M-\tau_{1} \frac{x^{2}}{R^{2}}-\tau_{2} \frac{(x-d)^{2}}{R^{2}}-\tau_{1}-\tau_{2}=0
\end{aligned}
$$

Through the integration of $x$ in the above equation, the unit compressive pressure in zone I can be obtained.

$$
\begin{aligned}
p_{\mathrm{I}}= & -\frac{2 m \sigma_{s}}{\sqrt{3} R} x+M \ln \left(2 x^{2}-2 d x+d^{2}+2 R h_{0}\right) \\
& -\frac{4 m \sigma_{s}\left(R-h_{0}\right)}{\sqrt{3 d^{2}+12 R h_{0}}} \arctan \frac{2 x-d}{\sqrt{d^{2}+4 R h_{0}}}+C_{\mathrm{I}}
\end{aligned}
$$

3.2.2. Zone II $\left(x_{n 2} \leq x \leq x_{n 1}\right)$. The forces in this zone have the following relationships:

$p_{1}=p+\tau_{1} \tan \theta_{1}, p_{2}=p-\tau_{2} \tan \theta_{2}, \tau_{e}=\tau_{2}-\tau_{1}$, and substituting them into (22), the following can be obtained.

$$
\begin{aligned}
& \left(h_{0}+\frac{x^{2}+(x-d)^{2}}{2 R}\right) \cdot \frac{d p}{d x} \\
& \quad=\frac{2 x-d}{R} M+\tau_{1} \frac{x^{2}}{R^{2}}-\tau_{2} \frac{(x-d)^{2}}{R^{2}}+\tau_{1}-\tau_{2}
\end{aligned}
$$

Through the integration of $x$ in the above equation, the unit compressive pressure in zone II can be obtained.

$$
\begin{aligned}
p_{\mathrm{II}}= & \left(M+\frac{\sigma_{s} m d}{\sqrt{3} R}\right) \ln \left(2 R h_{0}+2 x^{2}-2 d x+d^{2}\right) \\
& +C_{\mathrm{II}}
\end{aligned}
$$

3.2.3. Zone III $\left(d \leq x \leq x_{n 2}\right)$. The forces in this zone have the following relationships:

$p_{1}=p+\tau_{1} \tan \theta_{1}, p_{2}=p+\tau_{2} \tan \theta_{2}, \tau_{e}=-\tau_{1}-\tau_{2}$, and substituting them into (22), the following can be obtained.

$$
\begin{aligned}
& \left(h_{0}+\frac{x^{2}+(x-d)^{2}}{2 R}\right) \cdot \frac{d p}{d x} \\
& \quad=\frac{2 x-d}{R} M+\tau_{1} \frac{x^{2}}{R^{2}}+\tau_{2} \frac{(x-d)^{2}}{R^{2}}+\tau_{1}+\tau_{2}=0
\end{aligned}
$$

Through the integration of $x$ in the above equation, the unit compressive pressure in zone III can be obtained.

$$
\begin{aligned}
p_{\mathrm{III}}= & \frac{2 m \sigma_{s}}{\sqrt{3} R} x+M \ln \left(2 x^{2}-2 d x+d^{2}+2 R h_{0}\right) \\
& +\frac{4 m \sigma_{s}\left(R-h_{0}\right)}{\sqrt{3 d^{2}+12 R h_{0}}} \arctan \frac{2 x-d}{\sqrt{d^{2}+4 R h_{0}}}+C_{\mathrm{III}}
\end{aligned}
$$

3.2.4. Zone IV $(0 \leq x \leq d)$. The forces in this zone have the following relationships:

$p_{1}=p+\tau_{1} \tan \theta_{1}, p_{2}=0, \tau_{e}=-\tau_{1}$, and substituting them into (22), the following can be obtained.

$$
\left(h_{0}+\frac{x^{2}}{2 R}\right) \frac{d p}{d x}=\frac{x}{R} M+\tau_{1} \frac{x^{2}}{R^{2}}+\tau_{1}
$$

Through the integration of $x$ in the above equation, the unit compressive pressure in zone IV can be obtained.

$$
\begin{aligned}
p_{\mathrm{IV}}= & \frac{2 m \sigma_{s}}{\sqrt{3} R} x+M \ln \left(x^{2}+2 R h_{0}\right) \\
& +\frac{\sqrt{2} m \sigma_{s}\left(R-2 h_{0}\right)}{\sqrt{3 R h_{0}}} \arctan \frac{x}{\sqrt{2 R h_{0}}}+C_{\mathrm{IV}}
\end{aligned}
$$


3.3. The Rolling Force and Rolling Torque Modeling. There is a roll offset between the top and bottom work rolls during snake rolling, and angular velocities of the top and bottom work rolls are different. Consequently, the flow rule and the stress distribution of the mass point of the metal in the deformation zone are different from those of the symmetrical rolling and asymmetrical rolling.

The reverse deflection zone (zone IV) always exists because of the existence of the roll offset between the top and bottom work rolls. During snake rolling, the neutral point of the top work roll moves toward the inlet direction, and the neutral point of the bottom work roll moves toward the outlet direction. The directions of the friction force of the top and bottom surfaces of the rolled pieces are opposite when the neutral point of the top work roll moves to the inlet and the neutral point of the bottom work roll moves to the outlet. In this condition, the deformation zone is composed of cross shear zone (zone II) and reverse deflection zone (zone IV). The neutral point cannot move to the inlet or the outlet under some restrictions, and the back slip zone (zone I) or front slip zone (zone III) may appear in the deformation zone. At this time, the deformation zone is composed of back slip zone (zone I), cross shear zone (zone II), and reverse deflection zone (zone IV) or composed of back slip zone (zone I), cross shear zone (zone II), front slip zone (zone III), and reverse deflection zone (zone IV).

At the throwing point (point "O" in Figure 1) of the top work roll the boundary conditions are $x=0, q=0$, so $p_{\mathrm{IV}}=$ $\left(2 \sigma_{s} / \sqrt{3}\right) \sqrt{1-m^{2}}$ can be obtained. $C_{\text {IV }}$ can be obtained by substituting them into (35).

(1) The deformation zone is composed of cross shear zone (zone II) and reverse deflection zone (zone IV) when $\gamma_{1} \geq$ $\alpha_{1}, \gamma_{2}=0$. In this case, the boundary conditions in the inlet position are $x=l, q=0$, and then $p_{\mathrm{II}}=\left(2 \sigma_{s} / \sqrt{3}\right) \sqrt{1-m^{2}}$ can be obtained. $C_{\mathrm{II}}$ can be obtained by substituting these equations into (31).

As a rolled piece is in equilibrium along the vertical direction, the rolling forces of the top and bottom work rolls are equal; namely, $F_{1}=F_{2}=F$. Therefore, the unit compressive pressure of the top work roll should be used to calculate the rolling force. The rolling force can be obtained by integrating the unit compressive pressure along the contact arc.

$$
F=B\left(\int_{0}^{d} p_{\mathrm{IV}} d x+\int_{d}^{l} p_{\mathrm{II}} d x\right)
$$

The rolling torque can be obtained by calculating the torque of friction force along the contact arc of top and bottom work rolls.

$$
\begin{aligned}
& T_{1}=-R B \int_{0}^{l} m k d x=-R B m k l \\
& T_{2}=R B \int_{d}^{l} m k d x=R B m k(l-d)
\end{aligned}
$$

(2) The deformation zone is composed of back slip zone (zone I), cross shear zone (zone II), and reverse deflection zone (zone IV) when $\gamma_{1}<\alpha_{1}, \gamma_{2}=0$. In this case, the boundary conditions in the inlet position are $x=l, q=0$, so $p_{\mathrm{I}}=\left(2 \sigma_{s} / \sqrt{3}\right) \sqrt{1-m^{2}}$ can be calculated. $C_{\mathrm{I}}$ can be obtained by substituting these equations into (29).

Because $p_{\mathrm{II}}(x=d)=p_{\mathrm{IV}}(x=d)$ at $x=d, C_{\mathrm{II}}$ can be calculated. At $x=x_{n 1}, p_{\mathrm{I}}\left(x=x_{n 1}\right)=p_{\mathrm{II}}\left(x=x_{n 1}\right)$, so $x_{n 1}$ can be calculated by (29) and (31). The rolling force can be obtained by integrating the unit compressive pressure along the contact arc.

$$
F=B\left(\int_{0}^{d} p_{\mathrm{IV}} d x+\int_{d}^{x_{n 1}} p_{\mathrm{II}} d x+\int_{x_{n 1}}^{l} p_{\mathrm{I}} d x\right)
$$

The rolling torque can be obtained by calculating the torque of friction force along the contact arc of top and bottom work rolls.

$$
\begin{aligned}
T_{1} & =R B\left(\int_{x_{n 1}}^{l} m k d x-\int_{0}^{x_{n 1}} m k d x\right) \\
& =R B m k\left(l-2 x_{n 1}\right) \\
T_{2} & =R B\left(\int_{x_{n 1}}^{l} m k d x+\int_{d}^{x_{n 1}} m k d x\right)=R B m k(l-d)
\end{aligned}
$$

(3) The deformation zone is composed of back slip zone (zone I), cross shear zone (zone II), front slip zone (zone III), and reverse deflection zone (zone IV) when $\gamma_{1}<$ $\alpha_{1}, \gamma_{2}<\alpha_{2}$. In this case, the boundary conditions in the inlet position are $x=l, q=0$, so $p_{\mathrm{I}}=\left(2 \sigma_{s} / \sqrt{3}\right) \sqrt{1-m^{2}}$ can be calculated. $C_{\mathrm{I}}$ can be obtained by substituting these equations into (29). Because $p_{\mathrm{III}}(x=d)=p_{\mathrm{IV}}(x=d)$ at $x=d, C_{\mathrm{III}}$ can be calculated. At $x=x_{n 1}, p_{\mathrm{I}}\left(x=x_{n 1}\right)=p_{\mathrm{II}}\left(x=x_{n 1}\right)$, so $C_{\mathrm{II}}\left(x=x_{n 1}\right)$ can be calculated. At $x=x_{n 2}, p_{\mathrm{II}}\left(x=x_{n 2}\right)=p_{\mathrm{III}}\left(x=x_{n 2}\right)$, so $C_{\mathrm{II}}\left(x=x_{n 2}\right)$ can be calculated. Since the unit compressive pressure is continuous in the neutral points of the top and bottom work rolls, the following equations was obtained as below.

$$
C_{\mathrm{II}}\left(x=x_{n 1}\right)=C_{\mathrm{II}}\left(x=x_{n 2}\right)
$$

The volume remains constant during the rolling process, so the following relationship exists.

$$
v_{1} \cos \gamma_{1} h_{x_{n 1}}=v_{2} \cos \gamma_{2} h_{x_{n 2}}
$$

Therefore the equation can be obtained as below.

$$
\begin{gathered}
v_{1} \cdot \sqrt{1-\frac{x_{n 1}^{2}}{R^{2}} \cdot\left(h_{0}+\frac{x_{n 1}^{2}+\left(x_{n 1}-d\right)^{2}}{2 R}\right)} \\
=v_{2} \cdot \sqrt{1-\frac{\left(x_{n 2}-d\right)^{2}}{R^{2}}} \\
\cdot\left(h_{0}+\frac{x_{n 2}^{2}+\left(x_{n 2}-d\right)^{2}}{2 R}\right)
\end{gathered}
$$

By combining (42) and (44), $x_{\mathrm{n} 1}, x_{\mathrm{n} 2}$, and $C_{\mathrm{II}}$ can be obtained. 
The rolling force can be obtained by integrating the unit compressive pressure along the contact arc.

$$
\begin{aligned}
F & =B\left(\int_{0}^{d} p_{\mathrm{IV}} d x+\int_{d}^{x_{n 2}} p_{\mathrm{III}} d x+\int_{x_{n 2}}^{x_{n 1}} p_{\mathrm{II}} d x\right. \\
& \left.+\int_{x_{n 1}}^{l} p_{\mathrm{I}} d x\right)
\end{aligned}
$$

The rolling torque can be obtained by calculating the torque of friction force along the contact arc of top and bottom work rolls.

$$
\begin{aligned}
T_{1} & =R B\left(\int_{x_{n 1}}^{l} m k d x-\int_{x_{n 2}}^{x_{n 1}} m k d x-\int_{d}^{x_{n 2}} m k d x\right. \\
& \left.-\int_{0}^{d} m k d x\right)=R B m k\left(l-2 x_{n 1}\right) \\
T_{2} & =R B\left(\int_{x_{n 1}}^{l} m k d x+\int_{x_{n 2}}^{x_{n 1}} m k d x-\int_{d}^{x_{n 2}} m k d x\right) \\
& =R B m k\left(l+d-2 x_{n 2}\right)
\end{aligned}
$$

\section{Results and Discussions}

The numerical method has been used in the rolling process simulation by many scholars, and the calculating precision has been verified by many scholars. As a new rolling technology, the heavy steel plate snake rolling experiment is difficult to be conducted in the laboratory because of the equipment casts. In this case, the numerical method will be used to simulate the snake rolling process, and the rolling force can be obtained by the numerical method. The calculation precision of the analytical model can also be verified.

4.1. Numerical Modeling. A finite element method (Arbitrary Lagrangian-Eulerian, ALE) can be used to simulate the rolling process. The snake rolling process can be simulated by Ansys LS-DYNA (explicit dynamic analysis), and the element type selected is a 3D solid element (ID 164). The top and bottom work rolls are modeled as rigid body. The rolls can only rotate along their axis and the other rotational and translational directions are constrained. The heavy steel plate is modeled as a bilinear isotropic material and constrained by the contact between the work rolls and the heavy steel plate. Table 1 shows the initial data used in simulation and Figure 3 shows the meshing model used in the FEM (Finite Element Method) simulation. There are 253510 nodes and 196000 elements in the meshing model.

4.2. Analytical and Numerical Results Verifying and Discussions. Thirteen kinds of parameters as shown in Table 2 were selected for analytical and numerical calculation in order to verify the analytical results of the theoretical models setup in this paper. One of the time-snake rolling force curves was shown in Figure 4. Then the average rolling force can be obtained as listed in Table 2.

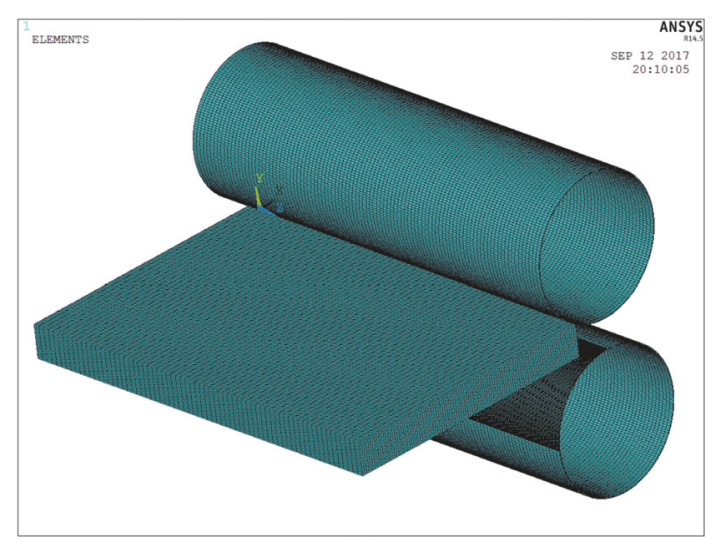

FIGURE 3: Meshing model used in the snake rolling process simulation.

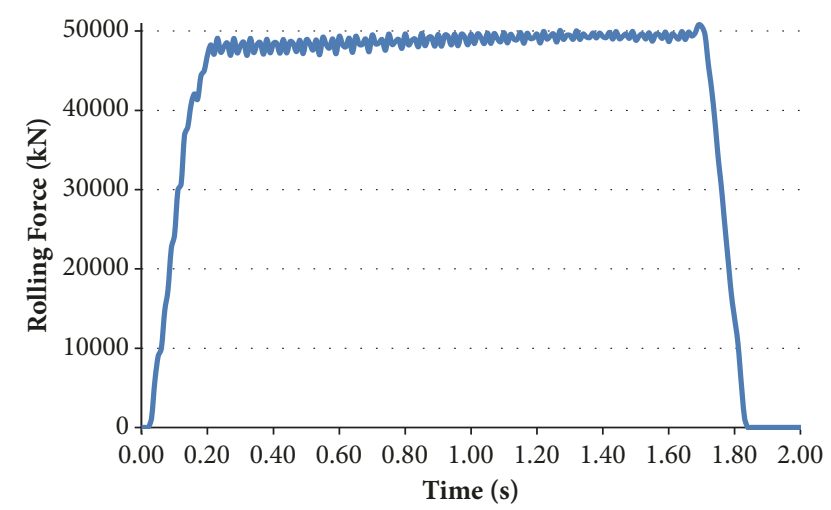

FIGURE 4: The time-rolling force curve when $v_{2}=1.325 \mathrm{~m} / \mathrm{s}$ and roll offset is $10 \mathrm{~mm}$.

The comparison of the relative deviation between the analytical results and the numerical results was shown in Table 2. The composition of the deformation zone with different process parameters was also given in Table 2. It can be seen that the roll speed ratio is the most critical process parameter that affects the composition of the deformation zone.

For the rolling parameters shown in Table 1 , the deformation zone is composed of back slip zone (zone I), cross shear zone (zone II), front slip zone (zone III), and reverse deflection zone (zone IV) when the roll speed ratio is less than 1.008. And the deformation zone is composed of back slip zone (zone I), cross shear zone (zone II), and reverse deflection zone (zone IV) when the roll speed ratio is greater than 1.008. Besides, the deformation zone is composed of cross shear zone (zone II) and reverse deflection zone (zone IV) when the roll speed ratio reaches 1.115.

The longer the length of the cross shear zone is, the more beneficial it is to the inner region deformation of the heavy steel plate. Moreover, it can refine inner region grains and reduce the rolling force. And the roll speed ratio can also affect the plate curvature after rolling. Therefore, appropriate roll speed ratio should be confirmed according 
TABLE 1: Data used in simulation.

\begin{tabular}{|c|c|c|}
\hline Items & Name & Value \\
\hline \multirow{3}{*}{ Mill parameters } & Work roll diameter $/ \mathrm{mm}$ & 1051 \\
\hline & Elastic modulus/ $G P a$ & 206 \\
\hline & Poisson ratio & 0.25 \\
\hline \multirow{8}{*}{ Rolled piece parameters (performance) } & Width $/ \mathrm{mm}$ & 3000 \\
\hline & Thickness $/ \mathrm{mm}$ & 250 \\
\hline & Length $/ \mathrm{mm}$ & 2000 \\
\hline & Rolling reduction $/ \mathrm{mm}$ & 32 \\
\hline & Yield stress $/ \mathrm{MPa}$ & 100 \\
\hline & Tangent modulus/MPa & 10 \\
\hline & Elastic modulus/ $G P a$ & 110 \\
\hline & Poisson ratio & 0.29 \\
\hline \multirow{3}{*}{ Other setting parameters } & Roll speed $/ m \cdot s^{-1}$ & 1.3 \\
\hline & Dynamic friction coefficient & 0.35 \\
\hline & Static friction coefficient & 0.4 \\
\hline
\end{tabular}

TABLE 2: The relative error of analytic and numerical calculations of rolling force.

\begin{tabular}{lccccccccccc}
\hline No. & $\begin{array}{c}v_{1} \\
(\mathrm{~m} / \mathrm{s})\end{array}$ & $\begin{array}{c}v_{2} \\
(\mathrm{~m} / \mathrm{s})\end{array}$ & $\begin{array}{c}\text { Reduction } \\
(\mathrm{mm})\end{array}$ & $\begin{array}{c}\text { Roll offset } \\
(\mathrm{mm})\end{array}$ & $\begin{array}{c}\text { Roll radius } \\
(\mathrm{mm})\end{array}$ & $\begin{array}{c}\text { plate } \\
\text { thickness } \\
(\mathrm{mm})\end{array}$ & $\begin{array}{c}\text { plate width } \\
(\mathrm{mm})\end{array}$ & $\begin{array}{c}\text { Rolling force(KN) } \\
\text { Analytical } \\
\text { results }\end{array}$ & $\begin{array}{c}\text { Numerical } \\
\text { results }\end{array}$ & $\begin{array}{c}\text { relative } \\
\text { deviation }\end{array}$ & $\begin{array}{c}\text { composition of } \\
\text { the deformation } \\
\text { zone }\end{array}$ \\
\hline 1 & 1.3 & 1.300 & 32 & 10 & 525.5 & 250 & 3000 & 48152 & 48727 & $1.18 \%$ & I II III IV \\
2 & 1.3 & 1.305 & 32 & 10 & 525.5 & 250 & 3000 & 48120 & 48547 & $0.88 \%$ & I II III IV \\
3 & 1.3 & 1.310 & 32 & 10 & 525.5 & 250 & 3000 & 48045 & 48389 & $0.71 \%$ & I II III IV \\
4 & 1.3 & 1.325 & 32 & 10 & 525.5 & 250 & 3000 & 47949 & 48065 & $0.24 \%$ & I II IV \\
5 & 1.3 & 1.325 & 32 & 15 & 525.5 & 250 & 3000 & 48863 & 48236 & $1.30 \%$ & I II IV \\
6 & 1.3 & 1.325 & 32 & 18 & 525.5 & 250 & 3000 & 49401 & 48382 & $2.10 \%$ & I II IV \\
7 & 1.3 & 1.325 & 32 & 20 & 525.5 & 250 & 3000 & 49756 & 48592 & $2.40 \%$ & I II IV \\
8 & 1.3 & 1.325 & 32 & 22 & 525.5 & 250 & 3000 & 50107 & 49011 & $2.24 \%$ & I II IV \\
9 & 1.3 & 1.45 & 32 & 10 & 525.5 & 250 & 3000 & 43857 & 46575 & $5.84 \%$ & II IV \\
10 & 1.3 & 1.45 & 32 & 15 & 525.5 & 250 & 3000 & 44849 & 47680 & $5.94 \%$ & II IV \\
11 & 1.3 & 1.45 & 32 & 18 & 525.5 & 250 & 3000 & 45442 & 48309 & $5.93 \%$ & II IV \\
12 & 1.3 & 1.45 & 32 & 20 & 525.5 & 250 & 3000 & 45836 & 48369 & $5.24 \%$ & II IV \\
13 & 1.3 & 1.45 & 32 & 22 & 525.5 & 250 & 3000 & 46229 & 48516 & $4.71 \%$ & II IV \\
\hline
\end{tabular}

to the plate curvature requirement and the plate deformation permeability requirement.

The curve of roll speed ratios-the rolling force is shown in Figure 5. Among them, figure (a) is a full-scale curve, and figure (b) is a partial enlarged view of figure (a). A good agreement is observed between analytic results and numerical results. The figure shows that the rolling force gradually decreases as the roll speed ratio increases. This is because as the roll speed ratio increases, the neutral point $x_{n 1}$ of the top work roll moves toward the inlet side of the deformation zone, and the neutral point $x_{n 2}$ of the bottom work roll moves toward the outlet side of the deformation zone. As a result, the length of the cross shear zone increases, resulting in the shearing effect on the rolled pieces strengthen, so the rolling force is reduced.

The curve of roll offset-the rolling force is shown in Figure 6. Among them, figure (a) is a full-scale curve, and figure (b) is a partial enlarged view of figure (a). A good agreement is observed between analytic results and numerical results. The figure shows that the rolling force gradually increases as the roll offset increases. This is because increasing the roll offset is equivalent to increasing the length of the reverse deflection zone; thereby the length of the deformation zone is increased.

The curve of roll speed ratio-the rolling torque is shown in Figure 7 when the deformation zone is composed of back slip zone (zone I), cross shear zone (zone II), front slip zone (zone III), and reverse deflection zone (zone IV). As can be seen from Figure 7, the rolling torque of the top work roll gradually decreases and the rolling torque of the bottom work roll gradually increases when the roll speed ratio increases. This is because the top work roll neutral point $x_{n 1}$ moves toward the inlet of the deformation zone and the bottom work roll neutral point $x_{n 2}$ moves toward the outlet of the deformation zone when the roll speed ratio increases. It can be seen from (46) and (47) that the rolling torque of the top 


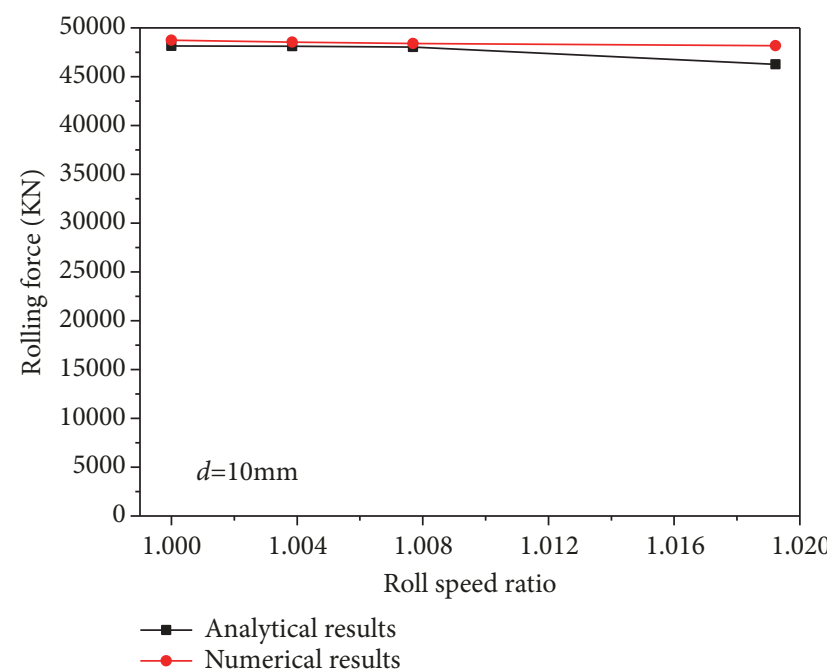

(a)

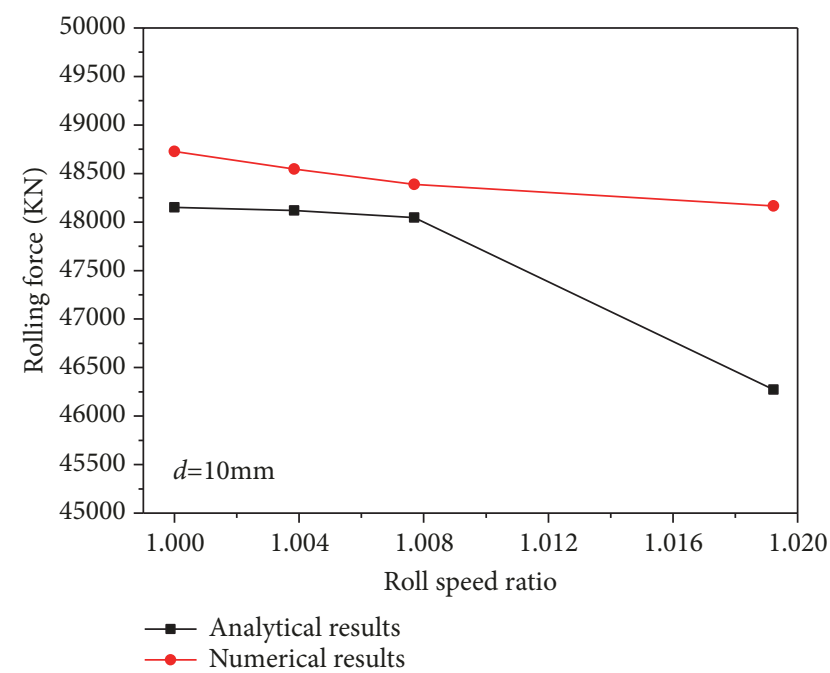

(b)

FIGURE 5: Curve of roll speed ratio-the rolling force.

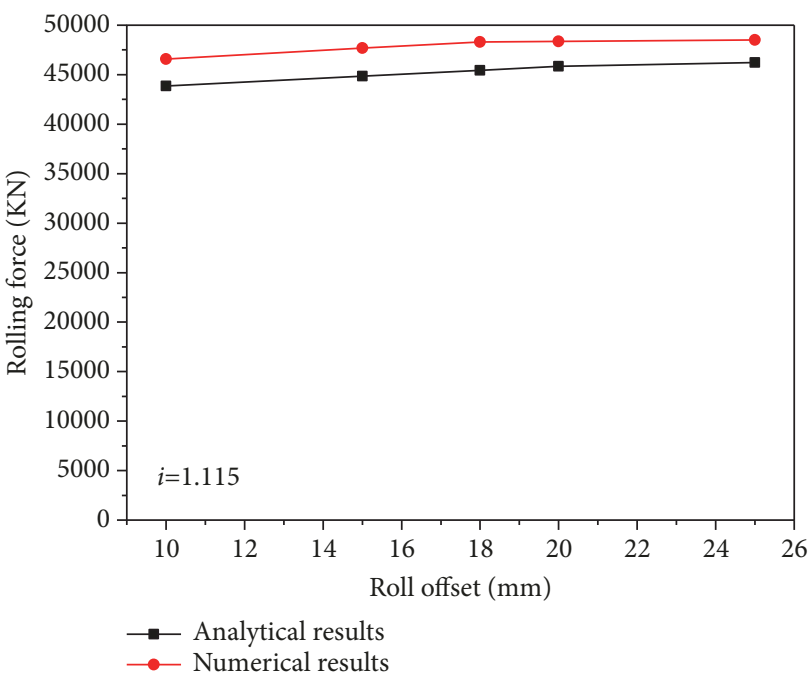

(a)

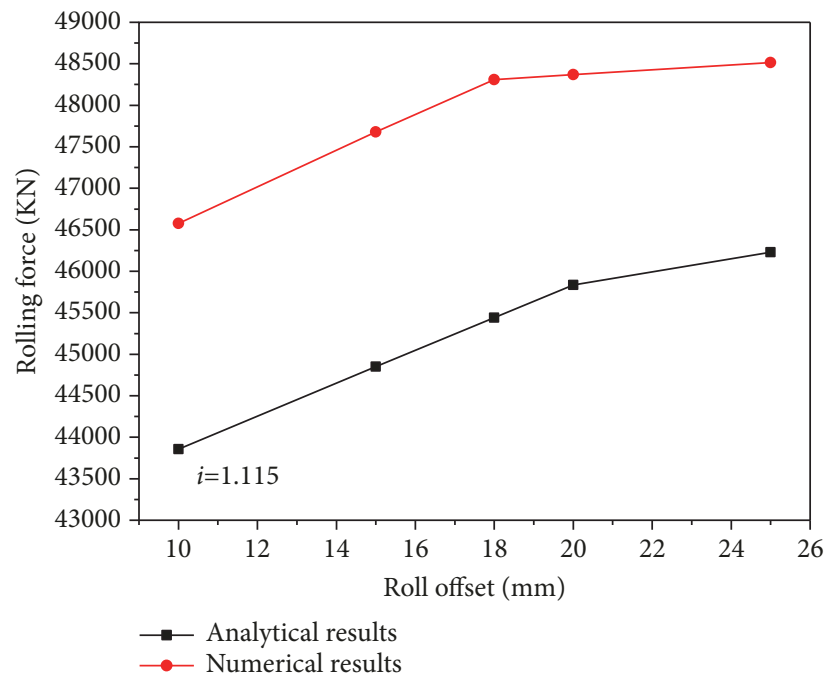

(b)

FIGURE 6: Curve of roll offset-the rolling force.

work roll decreases as the roll speed ratio increases, while the rolling torque of the bottom work roll increases as the roll speed ratio increases.

The curve of roll offset-the rolling torque is shown in Figure 8 when the deformation zone is composed of cross shear zone (zone II) and reverse deflection zone (zone IV). The figure shows that the rolling torques of the top and bottom work rolls are in the opposite direction. The rolling torque of the top work roll increases with the increase of the roll offset, while the rolling torque of the bottom work roll decreases with the increase of the roll offset. This is because increasing the roll offset is equivalent to increasing the length of the reverse deflection zone and thereby increasing the length of the deformation zone. It can be seen from (37) that the rolling torque of the top work roll increases as the roll offset increases. Although the increase of the roll offset $d$ is equivalent to increasing the length of the reverse deflection zone, the difference between the length of the deformation zone and the length of the reverse deflection zone $l-d$ is relatively reduced. It can be seen from (38) that the rolling torque of the bottom work roll decreases with the increase of the roll offset.

\section{Conclusions}

(1) The rolling deformation zone will be divided into back slip zone, front slip zone, cross shear zone, and reverse deflection zone according to the direction of the friction during 


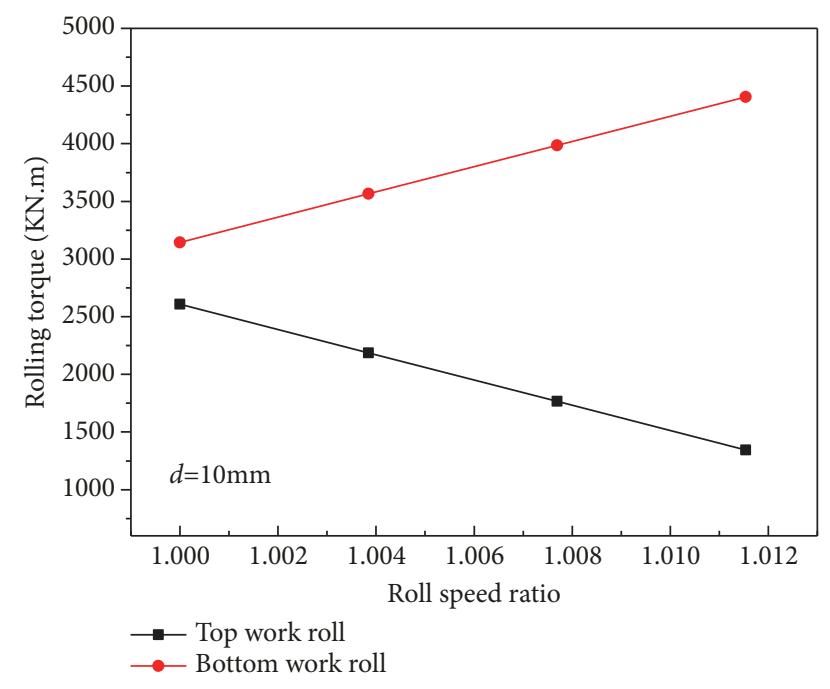

FIGURE 7: Curve of roll speed ratio-the rolling torque.

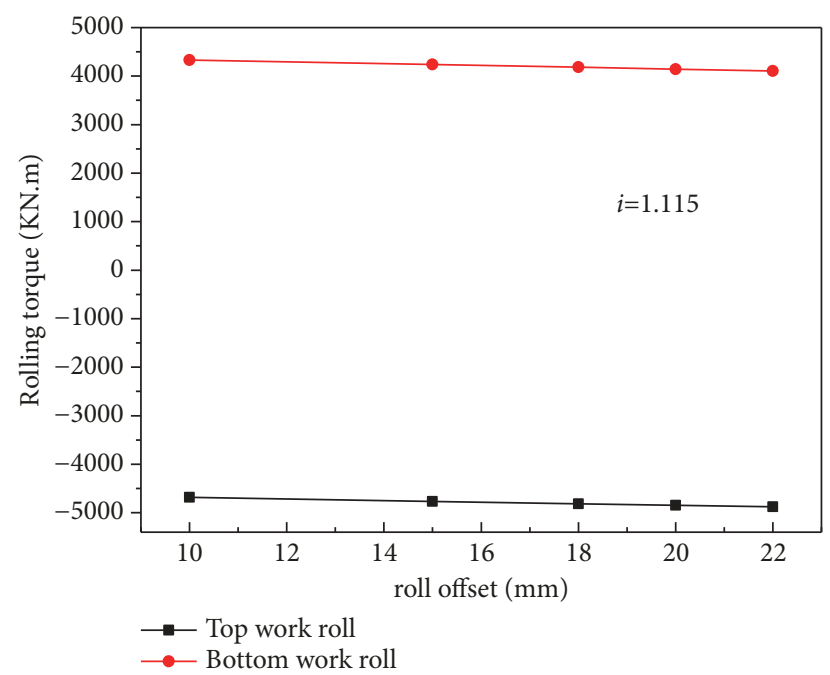

Figure 8: Curve of roll offset-the rolling torque.

snake rolling process. The calculating models that used to calculate mechanical parameters were set up on this basis: the calculated models of unit compressive pressure in every zone were set up by the slab method; the accurate calculating models of the rolling force and rolling torque were set up according to the composition of the rolling deformation zone and the boundary condition. The mechanical parameters were calculated by the analytical method and the numerical method, and the relative deviation between the analytical results and numerical results was less than $6 \%$ which can satisfy the industrial requirement.

(2) The reverse deflection zone always exists because of the existence of the roll offset between the top and bottom work rolls. The existence boundary conditions of the back slip zone, front slip zone, and cross shear zone was established according to the relationship between threading angle and neutral angle.
(3) The rolling force gradually decreases as the roll speed ratio increases when the deformation zone is composed of a back slip zone (zone I), cross shear zone (zone II), front slip zone (zone III), and reverse deflection zone (zone IV). The rolling torque of the top work roll gradually decreases and the rolling torque of the bottom work roll gradually increases as the roll speed ratio increases.

(4) The rolling torques of the top and bottom work rolls are in opposite directions when the deformation zone is composed of cross shear zone (zone II) and a reverse deflection zone (zone IV). The rolling torque of the top work roll increases, and the rolling torque of the bottom work roll decreases when the roll offset is increased.

\section{Nomenclature}

$R_{1}, R_{2}: \quad$ Radius of the top and bottom work roll $n_{1}, n_{2}: \quad$ Rotation rate of the top and bottom work roll

$d: \quad$ Roll offset

$\Delta h_{1}, \Delta h_{2}: \quad$ Reduction of the top and bottom work roll $l$ : $\quad$ Length of deformation zone

$H: \quad$ Initial plate thickness

$h_{0}$ : $\quad$ Plate thickness after rolling

$\triangle h: \quad$ Total reduction

$\alpha_{1}, \alpha_{2}: \quad$ Threading angle of the top and bottom work roll

$S_{1}, S_{2}: \quad$ Forward slip of the top and bottom work roll

$v_{0}: \quad$ Outlet velocity of steel plate

$v_{1}, v_{2}: \quad$ Linear velocity of the top and bottom work roll

$\gamma_{1}, \gamma_{2}: \quad$ Neutral angle of the top and bottom work roll

$\tau_{1}, \tau_{2}: \quad$ Surface shear stress at the top and bottom work roll

$\tau_{e}: \quad$ Resultant of surface shear stress

$\bar{\tau}_{1}, \bar{\tau}_{2}: \quad$ Mean shear stresses of top and bottom portions

$p: \quad$ Unit compressive pressure on differential slab element

$q$ : $\quad$ Horizontal normal stress in the

$p_{1}, p_{2}: \quad \begin{aligned} & \text { deformation zone } \\ & \text { Top and bottom roll pressures }\end{aligned}$

$\sigma_{s}: \quad$ Flow stress

$\sigma_{x}, \sigma_{y}, \sigma_{z}$ : Normal stress along the $x, y$ and $z$ axis

$\tau_{x y}, \tau_{y z}, \tau_{z x}$ : Shear stress in the $x y, y z$ and $z x$ plane

$m: \quad$ Friction factor

$k: \quad$ Mean yield shear stress

$\theta_{1}, \theta_{2}$ : Variable angles of contact of the top and bottom work roll

$x_{n 1}, x_{n 2}$ : Neutral point of top and bottom work roll

$h_{x_{n 1}}: \quad$ Steel plate thickness in the $x_{n 1}$ cross

$h_{x_{n 2}}: \quad \begin{aligned} & \text { section } \\ & \text { Steel plate thickness in the } x_{n 2} \text { cross }\end{aligned}$

section

$h: \quad$ Steel plate thickness in the $x$ cross section

B: $\quad$ Rolled piece width

$F: \quad$ Rolling force 
$T_{1}, T_{2}$ : Rolling torque of the top and bottom work roll.

\section{Data Availability}

The data used to support the findings of this study are available from the corresponding author upon request.

\section{Conflicts of Interest}

The authors declare that there are no conflicts of interest regarding the publication of this paper.

\section{Acknowledgments}

The authors gratefully appreciate the financial support by National Natural Science Foundation of China (Grant no. 51804206), Youth Science and Technology Research Fund of Shanxi Province in China (Grant no. 201601D202046), Scientific and Technological Innovation Programs of Higher Education Institutions in Shanxi (Grant no. 2016164), the doctoral promoter of Taiyuan University of Science and Technology in China (Grant no. 20152026), and the Open Research Fund from the State Key Laboratory of Rolling and Automation, Northeastern University (Grant No. 2017RALKFKT009).

\section{References}

[1] W. Yu, G. S. Li, and Q. W. Cai, "Effect of a novel gradient temperature rolling process on deformation, microstructure and mechanical properties of ultra-heavy plate," Journal of Materials Processing Technology, vol. 217, pp. 317-326, 2015.

[2] D. Pan and D. H. Sansome, "An experimental study of the effect of roll-speed mismatch on the rolling load during the cold rolling of thin strip," Journal of Mechanical Working Technology, vol. 6, no. 4, pp. 361-377, 1982.

[3] Y.-M. Hwang and G.-Y. I. Tzou, "Analytical and experimental study on asymmetrical sheet rolling," International Journal of Mechanical Sciences, vol. 39, no. 3, pp. 289-303, 1997.

[4] H. Gao, S. C. Ramalingam, G. C. Barber, and G. Chen, "Analysis of asymmetrical cold rolling with varying coefficients of friction," Journal of Materials Processing Technology, vol. 124, no. 1-2, pp. 178-182, 2002.

[5] Y. Fu, S. S. Xie, B. Q. Xiong et al., "Calculation of rolling force in snake rolling by slab method," Journal of Plasticity Engineering, vol. 17, no. 6, pp. 103-109, 2010.

[6] L. Jiang, C. Zhao, G. Yuan, J. Shi, and G. Wang, "Thicker steel plate shape-changing law and control method during the snake rolling process," Metallurgical Research \& Technology, vol. 113, no. 3, pp. 1-11, 2016.

[7] Y.-M. Hwang and G.-Y. Tzou, "An analytical approach to asymmetrical hot-sheet rolling considering the effects of the shear stress and internal moment at the roll gap," Journal of Materials Processing Technology, vol. 52, no. 2-4, pp. 399-424, 1995.

[8] Y. Hwang, T. Chen, and H. Hsu, "Analysis of asymmetrical clad sheet rolling by stream function method," International Journal of Mechanical Sciences, vol. 38, no. 4, pp. 443-460, 1996.

[9] G.-Y. Tzou and M.-N. Huang, "Study on minimum thickness for asymmetrical hot-and-cold PV rolling of sheet considering constant shear friction," Journal of Materials Processing Technology, vol. 119, no. 1-3, pp. 229-233, 2001.

[10] X. Liu, X.-H. Liu, M. Song, X.-K. Sun, and L.-Z. Liu, "Theoretical analysis of minimum metal foil thickness achievable by asymmetric rolling with fixed identical roll diameters," Transactions of Nonferrous Metals Society of China, vol. 26, no. 2, pp. 501-507, 2016.

[11] Y. Tian, Y. Guo, Z. Wang, and G. Wang, "Analysis of Rolling Pressure in Asymmetrical Rolling Process by Slab Method," Journal of Iron and Steel Research, International, vol. 16, no. 4, pp. 22-38, 2009.

[12] M. Salimi and F. Sassani, "Modified slab analysis of asymmetrical plate rolling," International Journal of Mechanical Sciences, vol. 44, no. 9, pp. 1999-2023, 2002.

[13] M. Salimi and M. Kadkhodaei, "Slab analysis of asymmetrical sheet rolling," Journal of Materials Processing Technology, vol. 150, no. 3, pp. 215-222, 2004.

[14] F. Afrouz and A. Parvizi, "An analytical model of asymmetric rolling of unbounded clad sheets with shear effects," Journal of Manufacturing Processes, vol. 20, pp. 162-171, 2015.

[15] M. Kadkhodaei, M. Salimi, and M. Poursina, "Analysis of asymmetrical sheet rolling by a genetic algorithm," International Journal of Mechanical Sciences, vol. 49, no. 5, pp. 622-634, 2007.

[16] S. H. Zhang, D. W. Zhao, C. R. Gao, and G. D. Wang, "Analysis of asymmetrical sheet rolling by slab method," International Journal of Mechanical Sciences, vol. 65, no. 1, pp. 168-176, 2012.

[17] S. Chen, H. Liu, Y. Peng, J. Sun et al., "Slab Analysis of Large Cylindrical Shell Rolling," Journal of Iron and Steel Research, International, vol. 21, no. 1, pp. 1-8, 2014.

[18] A. Parvizi, K. Abrinia, and M. Salimi, "Slab analysis of ring rolling assuming constant shear friction," Journal of Materials Engineering and Performance, vol. 20, no. 9, pp. 1505-1511, 2011.

[19] S. Li, N. Qin, J. Liu, and X. Zhang, "Microstructure, texture and mechanical properties of AA1060 aluminum plate processed by snake rolling," Materials \& Design, vol. 90, pp. 1010-1017, 2016.

[20] G. Xu, X. Cao, T. Zhang et al., "Achieving high strain rate superplasticity of an Al-Mg-Sc-Zr alloy by a new asymmetrical rolling technology," Materials Science and Engineering: A Structural Materials: Properties, Microstructure and Processing, vol. 672, pp. 98-107, 2016.

[21] T. Zhang, Y.-X. Wu, H. Gong, X.-Z. Zheng, and S.-S. Jiang, "Bending analysis and control of rolled plate during snake hot rolling," Journal of Central South University, vol. 22, no. 7, pp. 2463-2469, 2015.

[22] J. Yang, S. Li, J. Liu, X. Li, and X. Zhang, "Finite element analysis of bending behavior and strain heterogeneity in snake rolling of AA7050 plates using a hyperbolic sine-type constitutive law," Journal of Materials Processing Technology, vol. 240, pp. 274-283, 2017.

[23] T. Zhang, Y.-X. Wu, H. Gong, X.-Z. Zheng, and S.-S. Jiang, "Effects of rolling parameters of snake hot rolling on strain distribution of aluminum alloy 7075," Transactions of Nonferrous Metals Society of China, vol. 24, no. 7, pp. 2150-2156, 2014.

[24] Z. Tao, W. Yunxin, G. Hai, S. Wenze, J. Fangmin, and J. Shaosong, "Analysis of temperature asymmetry of aluminum alloy thick plate during snake hot rolling," The International Journal of Advanced Manufacturing Technology, vol. 87, no. 1-4, pp. 941-948, 2016.

[25] T. Zhang, Y.-X. Wu, H. Gong, W.-Z. Shi, and F.-M. Jiang, "Analysis of strain variation in cross shear zone of plate during snake hot rolling," Journal of Central South University, vol. 24, no. 2, pp. 296-302, 2017. 


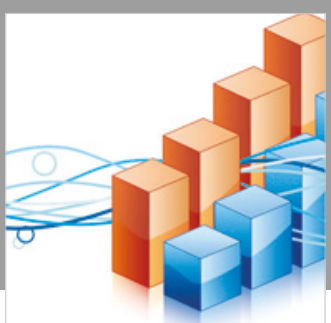

Advances in

Operations Research

\section{-n-m}
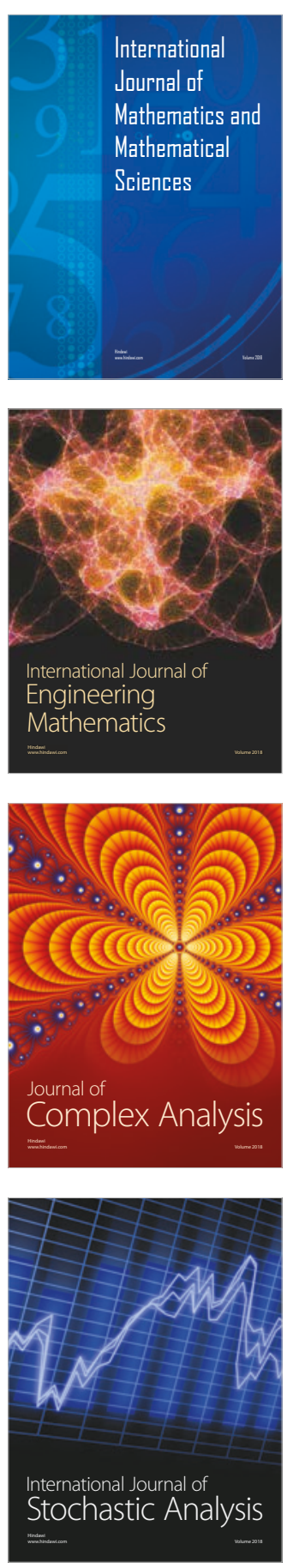
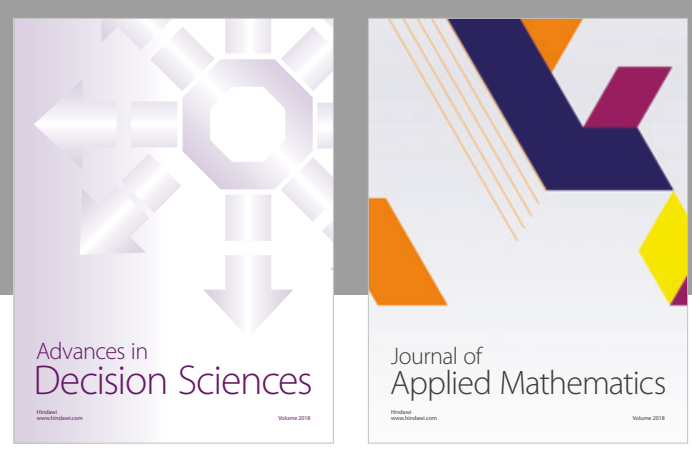

Journal of

Applied Mathematics
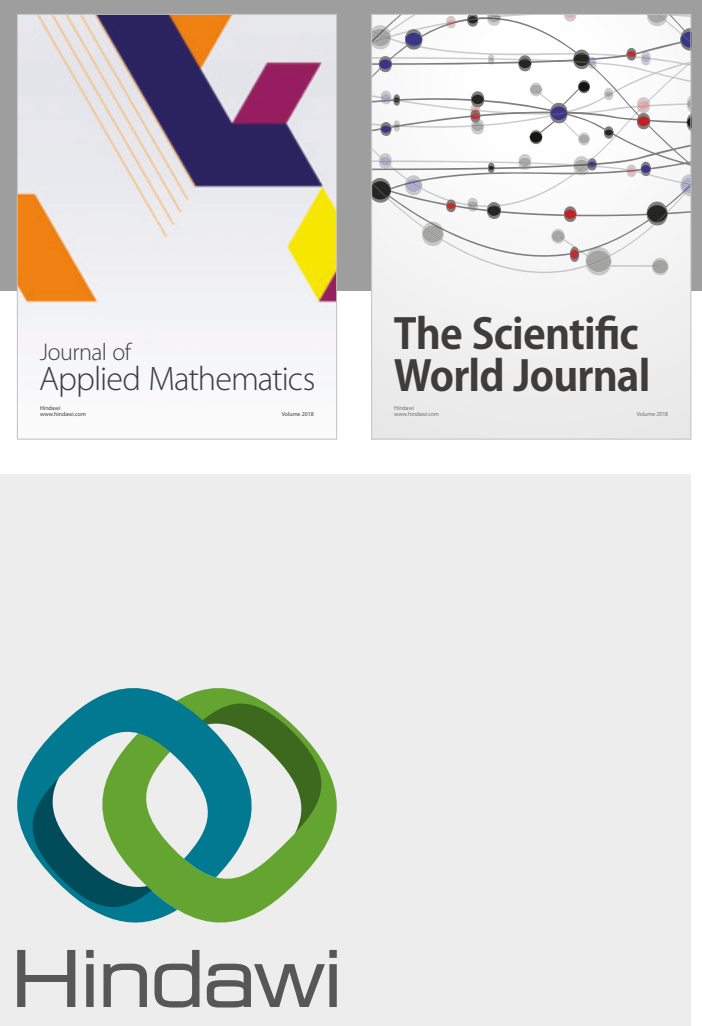

Submit your manuscripts at

www.hindawi.com

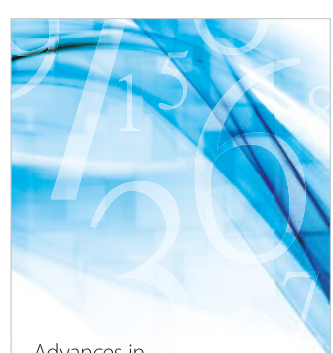

Advances in
Numerical Analysis
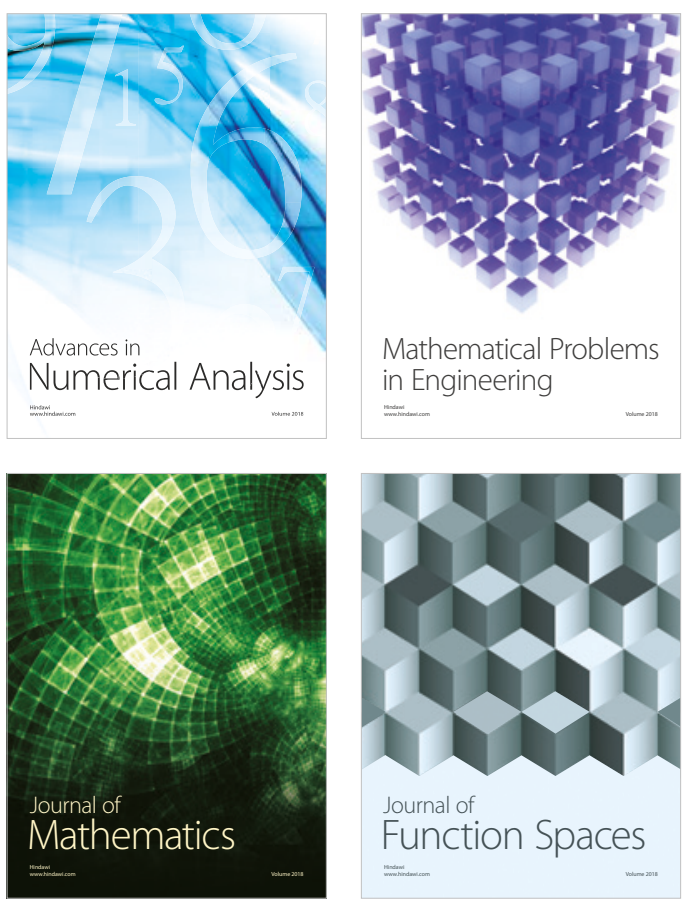

Mathematical Problems in Engineering

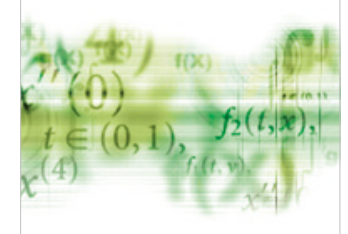

International Journal of

Differential Equations

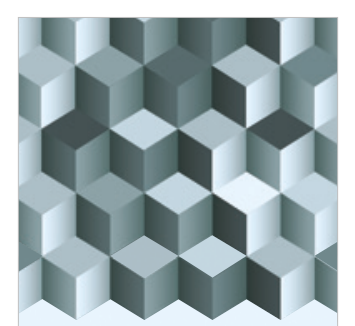

Journal of

Function Spaces

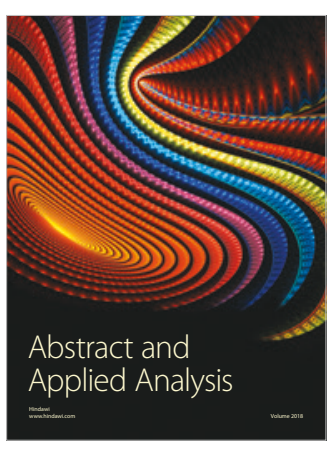

The Scientific

World Journal

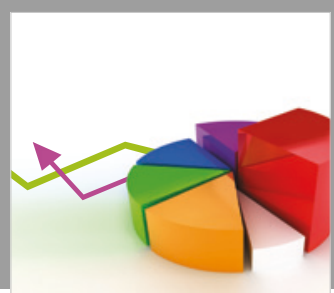

Journal of

Probability and Statistics
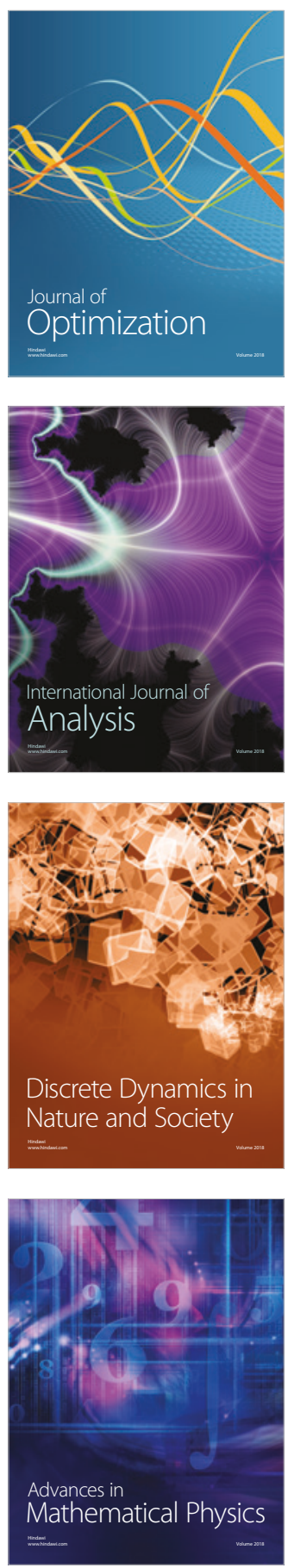